(C) 2003 IEEE. Personal use of this material is permitted. Permission from IEEE must be obtained for all other uses, in any current or future media, including reprinting/republishing this material for advertising or promotional purposes, creating new collective works, for resale or redistribution to servers or lists, or reuse of any copyrighted component of this work in other works. 


\title{
Experimental Determination of Stray Capacitances in High Frequency Transformers
}

\author{
Hai Yan $\mathrm{Lu}^{\#}$ Member IEEE, Jian Guo Zhu* Member IEEE, and \\ S.Y. Ron Hui+ Senior Member IEEE
}

\# Faculty of Information Technology

University of Technology, Sydney

P.O. Box 123, Broadway, NSW 2007

Australia

* Faculty of Engineering

University of Technology, Sydney

P.O. Box 123, Broadway, NSW 2007

Australia

Ph. +61295142318

Fax +61295142435

Email: joe@eng.uts.edu.au

+ Department of Electronic Engineering

City University of Hong Kong

Tat Chee Avenue

Hong Kong 


\section{ABSTRACT}

This paper presents practical techniques for determining stray capacitances in a two-winding high frequency transformer for circuit simulation and computer-aided design purposes. These techniques fall into two categories: the two-port network approach and the step-response approach. The first approach can be employed for high frequency transformer circuit models with the effect of stray capacitances modeled as a $\pi$-shape network of three lumped stray capacitances. The second approach is useful for the transformer circuit model with the overall effects of stray capacitances modeled as lumped stray-capacitance connected cross the primary side. These techniques have been verified in the modeling and numerical simulation of a $500 \mathrm{~W} 25 \mathrm{kHz}$ two winding E-core transformer. The merits and limitations of these techniques are also discussed.

Index terms: high frequency transformer, stray capacitance, and capacitance measurement 


\section{INTRODUCTION}

Stray capacitances in a high frequency transformer arise from the distributed or parasitic electrical coupling between any two conducting objects in or around the transformer. They can be classified as the turn-to-turn capacitance between two turns in the same winding or two different windings, the layer-to-layer capacitance between two layers in the same winding or two different windings, the capacitances between the windings and the magnetic core, and the capacitances between the windings and the ground, etc. They are heavily geometry-dependent and distributed in nature [1].

It has become widely aware that stray capacitances in high frequency magnetic components, such as inductors and transformers, have significant effects on the performance of the components as well as the entire power electronic systems that contain these magnetic components [1-2]. The stray capacitances significantly affect the magnetic component performance in such a way that the current waveform on the excitation side would be distorted and the overall efficiency of the system would be decreased. Furthermore, the stray capacitance seen from the excitation side is responsible for the resonant frequencies of the system whereas the stray capacitance between windings contributes to the EMI. These effects are very important in high voltage converters, and in topologies that intend to integrate the parasitic effects in the converter topologies.

Substantial attention has been focused on the modeling of stray capacitive effects in magnetic components in high frequency applications [3-12]. More popular models are the $\pi$-shaped network of three lumped capacitances, the three-port-network of six lumped capacitances, and the network of turn-to-turn based stray capacitance and inductance units. Recently, the authors have proposed a circuit model of high frequency transformers with the overall effect of stray capacitances modeled as a 
lumped stray capacitance [13]. Among these methods, the $\pi$-shaped network and single lumped stray capacitance models are more practical and convenient for the purposes of dynamic circuit modeling and numerical simulation while the other models are beneficial for computer-aided design purposes.

Many techniques for the determination of the lumped stray capacitances in high frequency magnetic components have been proposed in literature. The main approaches are: (1) the natural resonance approach [5-8], (2) the theoretical calculation based on the field analysis [9-10], and (3) analytical expressions approach using energy stored in electrostatic field based upon the electric field analysis [3]. The network theory underpins the first approach and an impedance analyzer is essential for the determination of multiple natural resonant frequencies of equivalent network of a high frequency transformer. The second approach needs a great amount of information about the geometry and electrostatic behavior of a high frequency transformer and sophisticated electric field analysis is essential. The third approach is useful mainly for transformers with certain specified geometric properties. As pointed out by Tescche, Ianoz and Karlsson [2], the parasitic parameters in a device, such as a transformer, were not well controlled at high frequencies and were typically highly geometry-dependent. If a high frequency analysis is desired, it is usually necessary that these parameters be measured experimentally.

The lumped stray capacitances in the circuit models of high frequency transformers are in fact frequency-dependent parameters due to the eddy currents generated in a conducting object in a time varying magnetic field. No methods proposed in literatures so far have taken this point into account. This paper focuses on experimental determination of stray capacitances in high frequency transformers and presents several experimental techniques for the determination of stray capacitances in two- 
winding transformers based on (1) the two-port network approach, and (2) the step response approach.

The two-port network approach identifies the stray capacitances of a two winding transformer by conducting the open and short circuit tests on both windings within the range of normal operating frequencies and then by fitting the $\pi$-shaped capacitor network model to the voltage and current readings. The step response approach identifies the stray capacitance from the stray capacitor current, which can be obtained by subtracting the inductor current from the total input current under a step or square wave voltage excitation. These techniques have been verified in the determination of stray capacitances in a $500 \mathrm{~W} 25 \mathrm{kHz}$ E-core transformer for the purpose of circuit modeling and numerical simulation.

\section{Circuit Models of Stray CaPACitanCES IN High FrequenCy TranSFORMERS}

Fig. 1 shows a two-winding transformer including the stray capacitance effects, where $R_{w 1}$ and $R_{w 2}$ are the resistances of the primary and secondary windings, $V_{1}$ and $V_{2}$ are the terminal voltages of the primary and secondary sides, and $C_{1 o}, C_{2 o}$ and $C_{12 o}$ are used to account for the self-capacitances of the primary and the secondary windings and the mutual capacitance between the two windings, respectively.

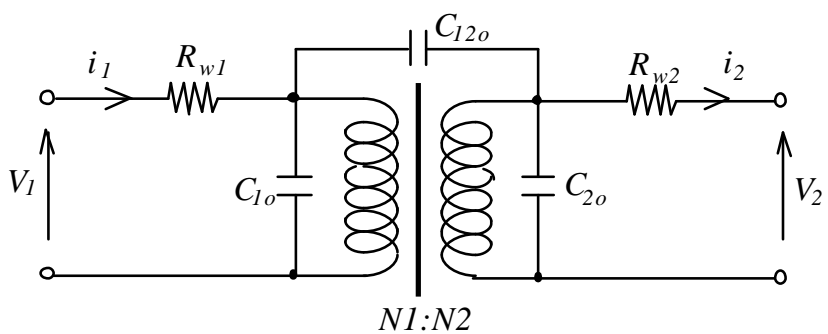

Fig.1 A two-winding transformer with stray capacitance effects included 
Fig.2 illustrates an equivalent electric circuit of a two-winding transformer shown in Fig.1 with all the secondary parameters referred to the primary side (indicated by '), where the $R_{w 1}, L_{l 1}$ and $R_{w 2}, L_{l 2}$ are the resistances and leakage inductances of the primary and secondary windings, respectively, $R_{m}$ is the equivalent core loss resistance, and $N_{l} \mathrm{~d} \Phi_{\mathrm{m}} / \mathrm{dt}$ is the back emf generated in the primary winding. The capacitances in Fig. 2 can be related to the capacitances in Fig.1 by

$$
\begin{aligned}
& C_{1}=C_{1 o}+(1-k) C_{12 o} \\
& C_{2}=k^{2} C_{2 o}+k(k-1) C_{12 o} \\
& C_{12}=k C_{12 o}
\end{aligned}
$$

where $k=N_{2} / N_{l}$.

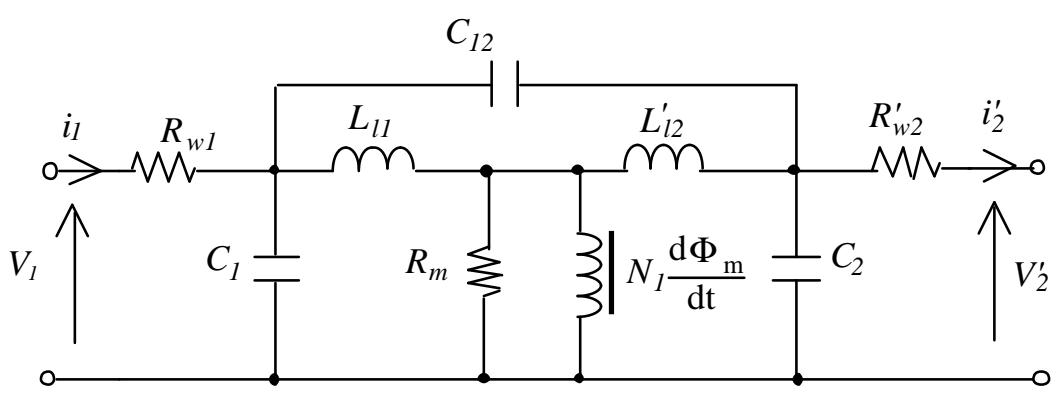

Fig.2 Equivalent circuit of a two-winding transformer shown in Fig.1 (referred to the primary side)

Since the leakage inductances in a high frequency transformer are small compared to the magnetization inductances in general. For example, a $500 \mathrm{~W}$ EE-core transformer $\left(N_{p}=10, N_{s}=8\right)$ operated under $25 \mathrm{kHz}$ square waveform excitation has leakage inductances of $1.01 \mu \mathrm{H}$ (including the inductance of the leads) for each winding (referred to the primary side) while the magnetization inductance is about $1.2 \mathrm{mH}$. The voltage drop across these leakage inductances is insignificant and hence the overall effect of the three stray capacitors can be simplified by an equivalent stray capacitor connected cross the primary side as shown in Fig.3. The single capacitance can be approximately related to the stray capacitances in Fig.2 by 


$$
C_{s t r} \approx C_{1}+C_{2}
$$

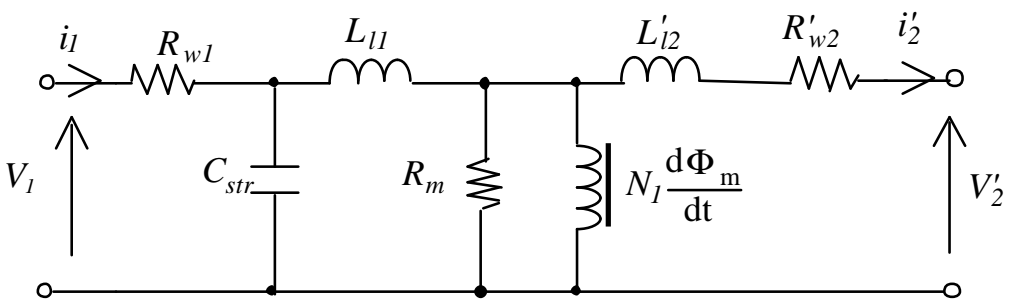

Fig.3 Equivalent circuit of a two-winding transformer with stray capacitance effects included as a single lumped stray capacitance cross over the primary terminals

\section{EXPERIMENTAL DETERMINATION OF LUMPED STRAY CAPACITANCES}

\subsection{Two-port Network Approach}

This approach treats an equivalent circuit of high frequency transformers as a two-port network and identifies the circuit parameters by using the open- and short-circuit impedances which can be easily measured under sinusoidal excitations. In order to eliminate the influence of magnetic non-linearity on the measurement of stray capacitance, the test should be performed on the windings separated from the magnetic core if possible. In case the windings cannot be separated from the core, the excitation current applied to the windings should be small such that the operating point of the core stays within the linear region.

\section{A. An Equivalent Two-Port Network of High Frequency Transformers}

The equivalent electrical circuit of a two-winding transformer with a linear magnetic core can be considered as a two-port network as shown in Fig.4, in which $V_{l}$ and $I_{l}$ are the voltage and current at port 1 (the primary side), $V_{2}^{\prime}$ and $I_{2}^{\prime}$ are the voltage and current at port 2 (secondary side) referred to the primary side, respectively. 


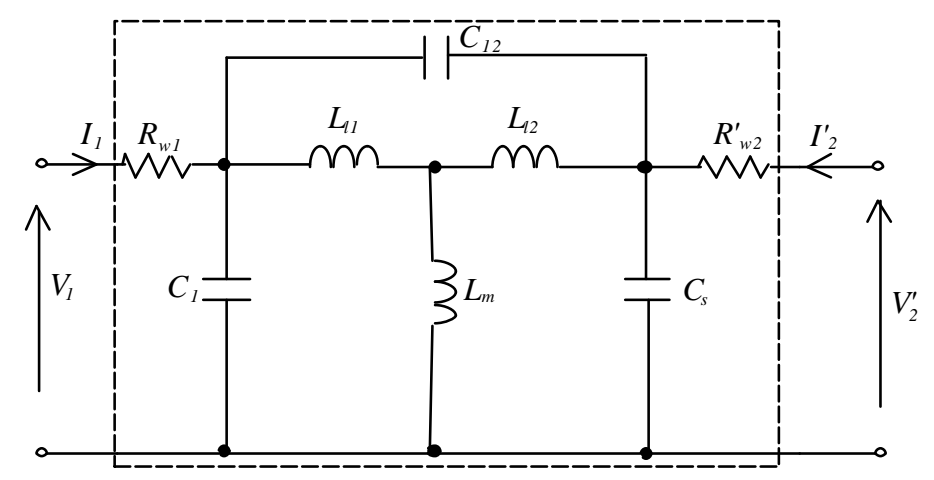

Fig.4 Equivalent two-port network of a two winding transformer

Under sinusoidal excitations, the network equations relating the terminal voltages and currents can be written in a matrix form as

$$
\mathbf{Y} \bullet \mathbf{V}=\mathbf{I}
$$

where $\mathbf{V}=\left[\mathrm{V}_{1}, \mathrm{~V}_{2}^{\prime}\right]^{\mathrm{T}}$ and $\mathbf{I}=\left[\mathrm{I}_{1}, \mathrm{I}_{2}^{\prime}\right]^{\mathrm{T}}$ are the terminal voltage and current vectors of the network, and $\mathbf{Y}$ is the admittance matrix, which can be expressed as

$$
\mathbf{Y}=\mathbf{A}^{-1} \bullet \mathbf{B}=\left[\begin{array}{ll}
A_{11} & A_{12} \\
A_{21} & A_{22}
\end{array}\right]^{-1} \bullet\left[\begin{array}{ll}
B_{11} & B_{12} \\
B_{21} & B_{22}
\end{array}\right]
$$

where

$$
\begin{aligned}
& A_{11}=R_{w 1}+j \omega\left(L_{l 1}+L_{m}\right)-\omega^{2} R_{w 1}\left(C_{p s} L_{l 1}+\left(L_{l 1}+L_{m}\right) C_{p}\right) \\
& A_{12}=j \omega L_{m}+\omega^{2} C_{p s} R_{w 2}^{\prime}\left(L_{l 1}+L_{m}\right)-\omega^{2} L_{m} R_{w 2}^{\prime}\left(C_{s}+C_{p s}\right) \\
& A_{21}=j \omega L_{m}+\omega^{2} C_{p s} R_{w 1}\left(L_{l 1}+L_{m}\right)-\omega^{2} L_{m} R_{w 1}\left(C_{p}+C_{p s}\right) \\
& A_{22}=R_{w 2}{ }^{\prime}+j \omega\left(L_{l 2}{ }^{\prime}+L_{m}\right)-\omega^{2} R_{w 2}{ }^{\prime}\left(C_{p s} L_{l 2}{ }^{\prime}+\left(L_{l 2}{ }^{\prime}+L_{m}\right) C_{s}\right)
\end{aligned}
$$

and

$$
\begin{aligned}
& B_{11}=1-\omega^{2}\left(C_{p s} L_{l 1}+\left(L_{l 1}+L_{m}\right) C_{p}\right) \\
& B_{12}=\omega^{2}\left(L_{l 1} C_{p s}-L_{m} C_{s}\right) \\
& B_{21}=\omega^{2}\left(L_{l 2}{ }^{\prime} C_{p s}-L_{m} C_{p}\right) \\
& B_{22}=1-\omega^{2}\left(C_{p s} L_{l 2}{ }^{\prime}+\left(L_{l 2}{ }^{\prime}+L_{m}\right) C_{s}\right)
\end{aligned}
$$




\section{B. Parameter Identification}

By the theory of two-port networks, the elements of the $\mathbf{Y}$ matrix can be experimentally determined by open and/or short circuit tests on both ports. The equivalent circuit parameters of the transformer can then be deduced from the $\mathbf{Y}$ matrix. In practice, the circuit parameters are obtained by applying the circuit equation (5) to the open- and short-circuit test data directly. Table 1 lists the circuit equations derived from (5) under open- and short-circuit conditions, where subscripts $o 1, o 2, s 1$, and $s 2$ stand for open-circuit port 1, open-circuit port 2, short-circuit port 1, and short-circuit port 2, respectively. There are two possible ways to determine the inductive and capacitive parameters in the circuit shown in Fig.4. One method is to use one set of open- and short-circuit test data from both ports at a specified frequency, and the other is to use multiple sets of open- and short-circuit test data from both ports within a specified frequency range. While the former can determine the parameters just for the specified frequency, the latter gives the parameters that fit to the whole frequency range on an average basis.

\section{Practical Identification Methods}

\section{Method A: Identifying circuit parameters for a single frequency}

This method identifies the circuit parameters for a specified frequency. It requires only one set of open- and short-circuit test data from both ports at the specified frequency. The inductances and stray capacitances are obtained by applying the circuit equations listed in Table 1 to the responses of the network under open- and short-circuit conditions. The dependence of the parameters on the excitation frequency caused by proximity effects can be taken into account by this method. 
Table 1. Reduced circuit equations for open and short circuit tests

\begin{tabular}{|c|c|c|}
\hline Tests & \multicolumn{2}{|c|}{ Circuit equations } \\
\hline $\begin{array}{c}\text { Port } 2 \text { open circuited, } \\
\mathrm{I}_{2}^{\prime}=0\end{array}$ & $I_{1 o s}=\frac{B_{21} B_{12}-B_{11} B_{22}}{A_{21} B_{12}-A_{11} B_{22}} V_{\text {los }}$ & $V_{2 o s}=\frac{A_{11} I_{1 o s}-B_{11} V_{1 o s}}{B_{12}}$ \\
\hline $\begin{array}{c}\text { Port } 2 \text { short circuited, } \\
\mathrm{V}_{2}^{\prime}=0\end{array}$ & $I_{1 s s}=\frac{B_{21} A_{12}-B_{11} A_{22}}{A_{21} A_{12}-A_{11} A_{22}} V_{1 s s}$ & $I_{2 s s}=\frac{B_{22} V_{1 s s}-A_{11} I_{1 s s}}{A_{12}}$ \\
\hline $\begin{array}{c}\text { Port } 1 \text { short circuited, } \\
\mathrm{V}_{1}=0\end{array}$ & $I_{2 s p}=\frac{A_{11} B_{22}-A_{21} B_{12}}{A_{22} A_{11}-A_{21} A_{21}} V_{2 s p}$ & $I_{1 s p}=\frac{B_{12} V_{2 s p}-A_{12} I_{2 s p}}{A_{11}}$ \\
\hline $\begin{array}{c}\text { Port 1 open circuited, } \\
\mathrm{I}_{1}=0\end{array}$ & $I_{2 o p}=\frac{B_{11} B_{22}-B_{12} B_{21}}{A_{22} B_{11}-A_{12} B_{21}} V_{2 o p p}$ & $V_{1 o p}=\frac{A_{12} I_{2 o p}-B_{12} V_{2 o p}}{B_{11}}$ \\
\hline
\end{tabular}

Method B: Identifying the circuit parameters over a range of frequencies on an average basis

This method is similar to Method A except that it identifies the circuit parameters by applying the circuit equations listed in Table 1 to a group of experimental data sets obtained by the open- and short-circuit tests from both ports over a range of frequencies from a few kilo Hertz to several hundred kilo Hertz. The identified circuit parameters may not fit exactly to the experimental data for a single frequency since they are actually the average values over the test frequency range. This method accounts for the proximity effect on an average-value basis.

\subsection{Step Response Approach}

This approach determines the single lumped stray capacitance $C_{s t r}$ of a two winding transformer from its step response with the secondary side open circuited as shown in Fig.5, where the secondary side open circuited transformer is treated as a single coil inductor with a vertical bar at the right hand side indicating the non-linear nature of the magnetic core, $V_{s}$ and $i_{s}$ are the excitation voltage and current, respectively, $i_{C}$ is the current passing through the stray capacitance, and $i_{L}$ is the magnetization current. 


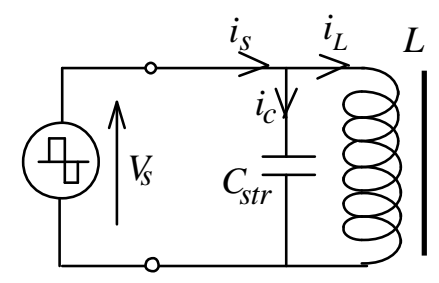

Fig.5 A single coil inductor with stray capacitance under a square waveform excitation

When the inductor is excited by a square wave voltage, the corresponding excitation current $i_{s}(t)$ can be recorded by a digital oscilloscope. The capacitive current $i_{c}(t)$ can be obtained by subtracting the inductive current $i_{L}(t)$ from the excitation aurrent $i_{s}(t)$, where $i_{L}(t)$ can be precisely calculated by a generalized dynamic ladder network model of high frequency magnetic core without stray capacitance [13]. Fig.6(a) shows the excitation voltage, the measured excitation current $i_{s}(t)$ and the predicted inductive current $i_{L}(t)$. The capacitor current $i_{c}(t)$, which is the difference between $i_{s}(t)$ and $i_{L}(t)$, is depicted in Fig.6(b).

The current passing through a capacitor $i_{c}(t)$ can be theoretically expressed as

$$
i_{c}(t)=C_{s t r} \frac{d V_{c}(t)}{d t}
$$

where $V_{c}(t)$ is the voltage across the capacitor $C_{s t r}$ and can be determined accordingly by

$$
V_{c}(t)=V_{c}\left(t_{0}\right)+\frac{1}{C_{s t r}} \int_{t_{0}}^{t} i_{c}(t) d t
$$

$t_{0}$ is the start time, $t$ the current time, and $V_{c}\left(t_{0}\right)$ the voltage across the capacitance at time $t_{0}$. Therefore, the stray capacitance $C_{s t r}$ can be calculated by

$$
C_{s t r}=\frac{\Delta t I_{c}}{\Delta V_{c}}
$$

where $\Delta t$ is the time increment (normally the switching time), $\Delta V_{c}=V_{c}\left(t_{0}+\Delta t\right)-V_{c}\left(t_{0}\right)$ the variation of $V_{c}$ during $\Delta t$, and 


$$
I_{c}=\frac{1}{\Delta t} \int_{t_{o}}^{t_{0}+\Delta t} i_{c}(t) d t
$$

is the averaged capacitive current over $\Delta t$.

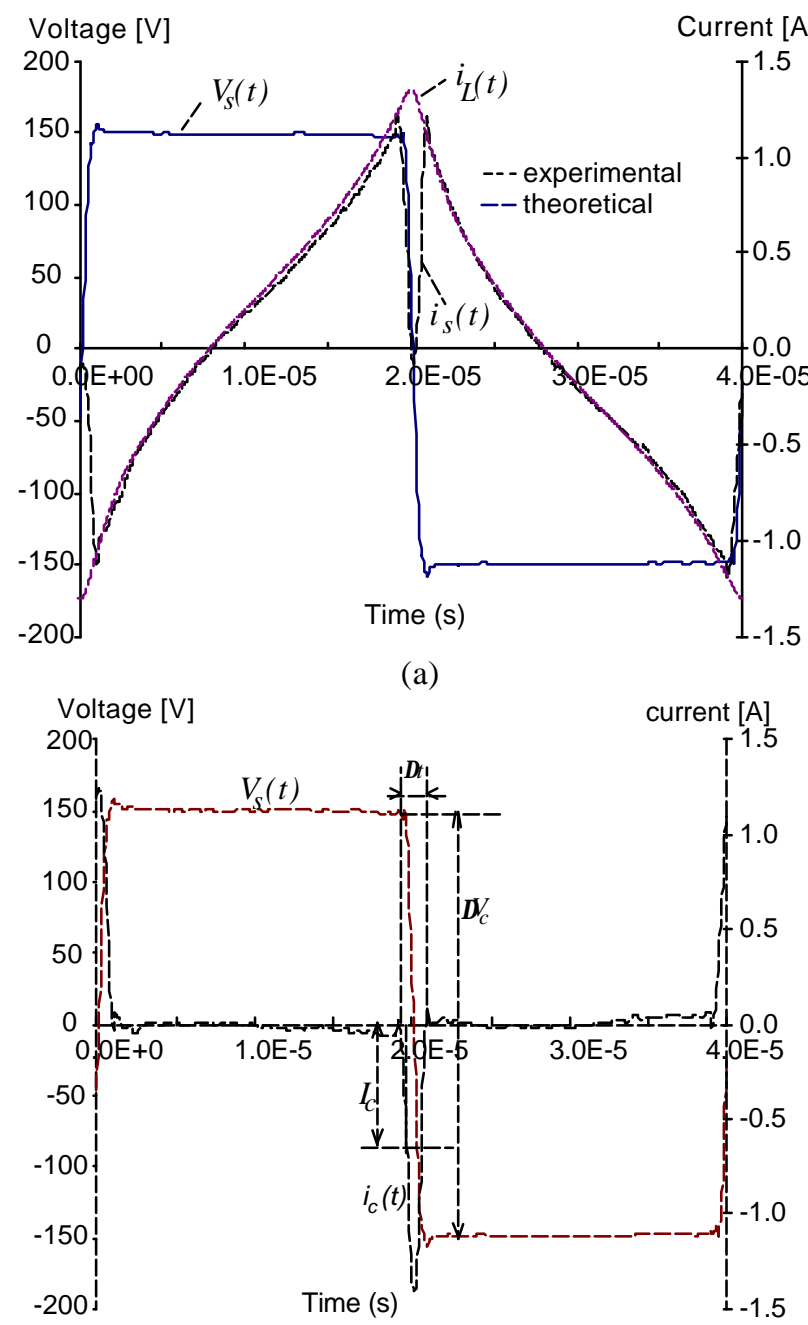

(b)

Fig.6 (a) Comparison of measured and predicted primary current, and

(b) Excitation voltage and deduced current through stray capacitance

\subsection{Experimental Verification}

To verify the experimental techniques presented in the above section, the stray capacitances of a test transformer, which is a commercial $500 \mathrm{~W} 25 \mathrm{kHz}$ EE-core two-winding transformer used in a telecommunication system (provided by ex-EXCOM, Australia), were determined from the two-port network approach and the step-response approach, respectively. The parameters of the test transformer are tabulated in Table 2. 
Table 2. Parameters of a $500 \mathrm{~W} 25 \mathrm{kHz}$ EE core transformer

\begin{tabular}{||l|l||}
\hline Core Material & Soft ferrite N27 (Siemens) \\
\hline \multirow{2}{*}{ Winding Material } & Copper foil, $0.10 \mathrm{~mm}$ thick, for both primary and secondary \\
& windings \\
\hline \multirow{2}{*}{ Number of Turns } & Primary winding: 10 turns \\
& Secondary winding: $8 \mathrm{turns}$ \\
\hline \multirow{2}{*}{ Winding Resistance (DC) } & Primary winding: $0.014 \Omega$ \\
& Secondary winding: $0.012 \Omega$ \\
\hline Insulation Material & NOMEX T410, thickness: $80 \mu \mathrm{m}$, and width: $44 \mathrm{~mm}$ \\
\hline
\end{tabular}

\section{$\underline{\text { Two-port network approach }}$}

The responses of the test transformer to sinusoidal voltage excitations under open- and short-circuit conditions were measured on both sides of the test transformer at frequencies ranging from a $2.56 \mathrm{kHz}$ to $496 \mathrm{kHz}$. Fig.7 illustrates the schematic of the testing system. In this system, the sinusoidal voltage signal produced by a function generator was fed into a power amplifier, which provides the excitation voltage to one of the windings of the transformer while the other winding was open- or short-circuited according to the test being performed. A digital power analyzer (PM3000A) was used to measure the voltage, current and real power on the excited side, which was connected to channel 1 (Ch.1), and the voltage (for open circuit tests only) on the non-excited side, which was connected to channel 2 (Ch.2). In a short circuit test, the short circuit current on the non-excited side was recorded by using a digital oscilloscope (YOKOGAWA DL1200A) with a current probe. Figs.8-9 present some of the measured results from the open- and short-circuit tests, respectively.

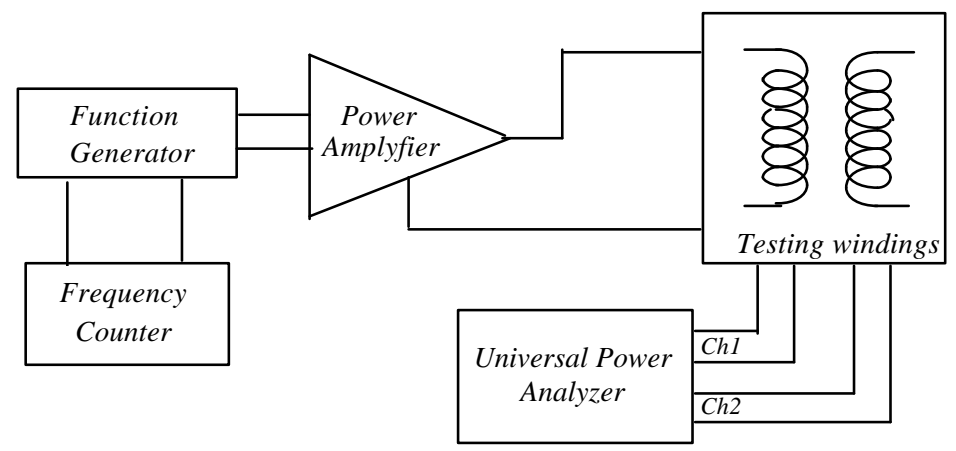

Fig.7 Schematic of the testing system 


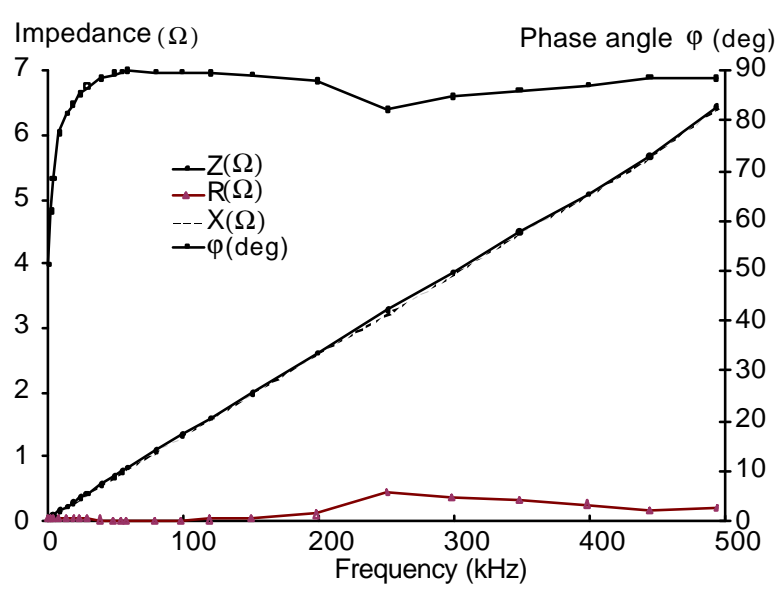

(a) Open secondary side

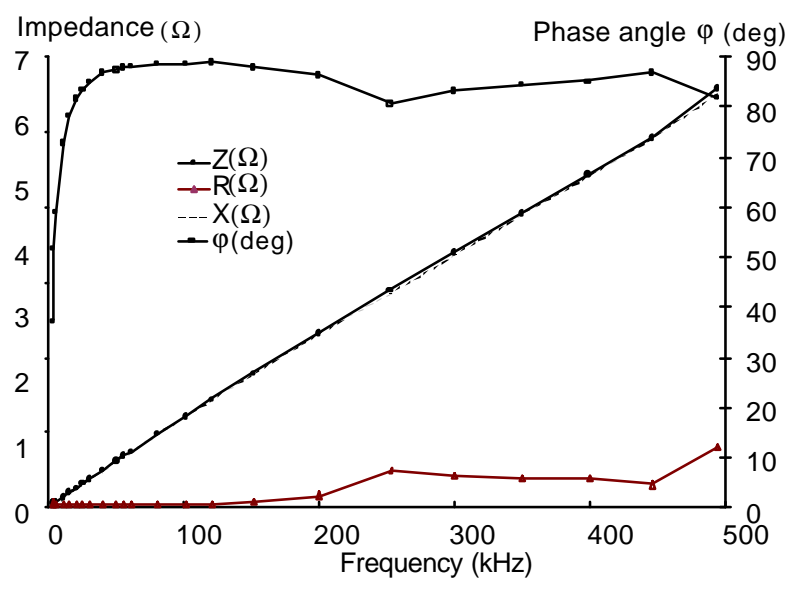

(b) Open primary side

Fig. 8 The resistance, reactance, impedance and phase angle measured from the excitation side while the non-excitation side is open circuited

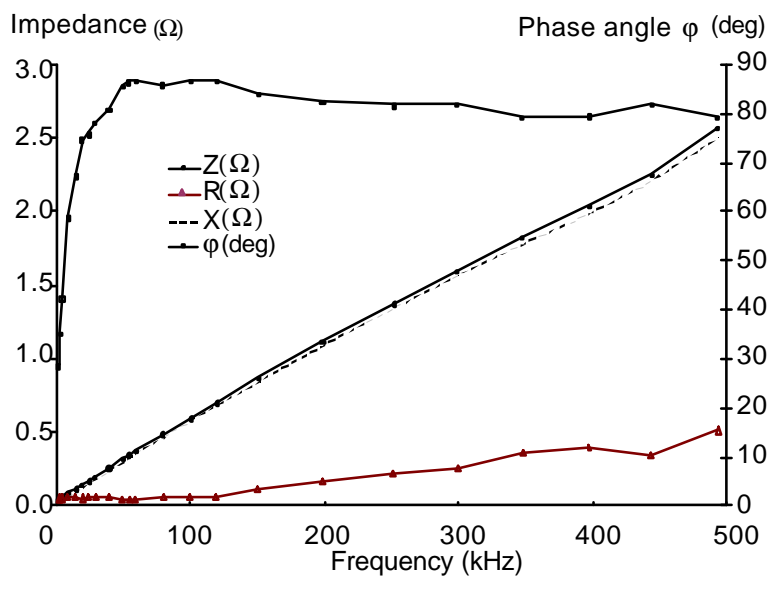

(a) Secondary side short-circuited

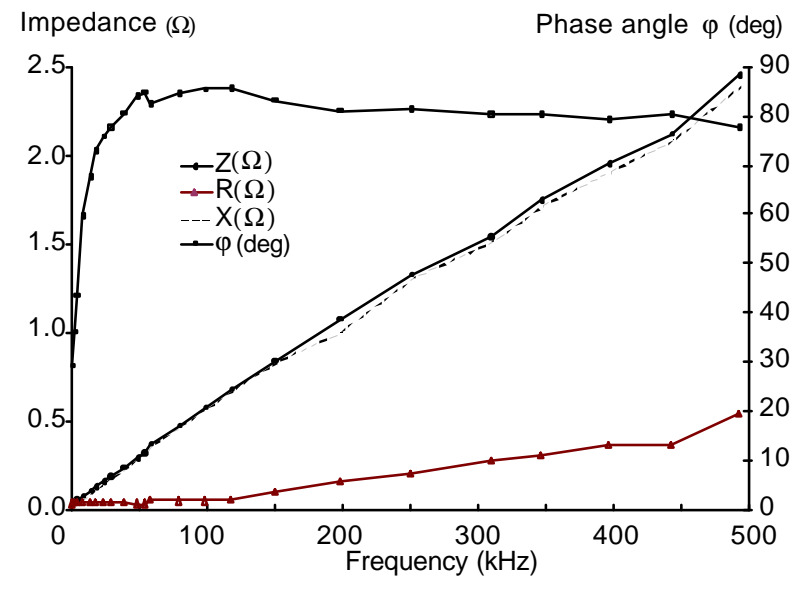

(b) Primary side short-circuited

Fig.9 The resistance, reactance, impedance and phase angle measured from the excitation side while the non-excitation side is short-circuited

Using Method A, the stray capacitances and inductances were determined by fitting the network model (see equations listed in Table 1) to the open- and short-circuit data at one frequency at a time. Twenty-three tests were carried out over the frequency range from $2.56 \mathrm{kHz}$ to $496 \mathrm{kHz}$ and the measured parameters are plotted in Fig.10. It is shown that the stray capacitances are almost constant except for some oscillation at very low frequencies, which can be attributed to the error of measurement. The average values of the inductances and stray capacitances are listed in Table 3 under column Method A. 


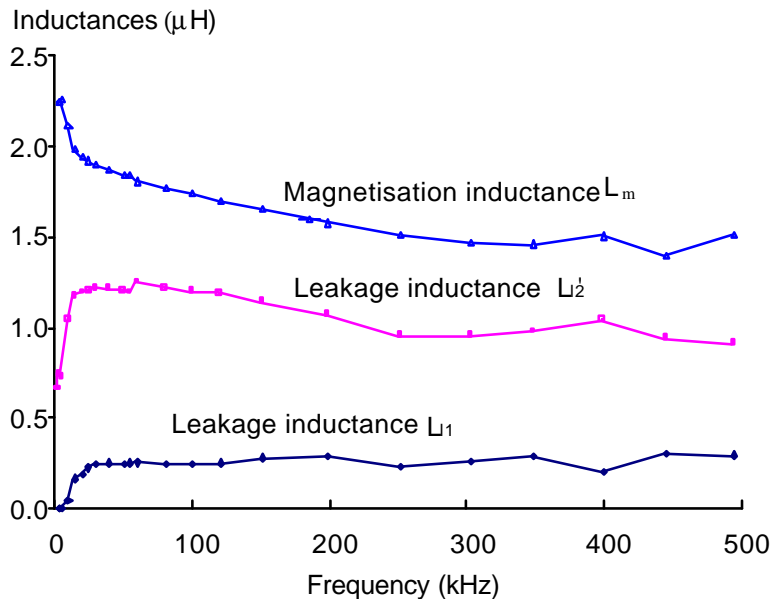

(a) Inductances $L_{l l}, L_{l 2}^{\prime}$ and $L m$

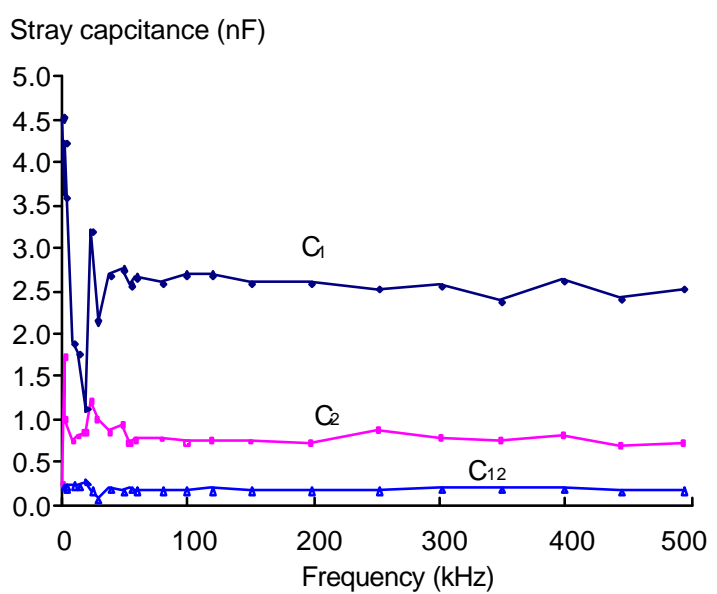

(b) Stray capacitances $\mathrm{C}_{1}, \mathrm{C}_{2}$ and $\mathrm{C}_{12}$ Fig.10 Parameters identified by Method A

Table 3. The inductances and stray capacitances of the test transformer by Method A and Method B

\begin{tabular}{|c|c|c|}
\hline Methods & Method A (averaged) & Method B \\
\hline$C_{1}(\mathrm{nF})$ & 2.652 & 2.688 \\
\hline$C_{2}(\mathrm{nF})$ & 0.816 & 0.770 \\
\hline$C_{12}(\mathrm{nF})$ & 0.172 & 0.197 \\
\hline$L_{l 1}(\mu \mathrm{H})$ & 0.209 & 0.241 \\
\hline$L_{l 2}{ }^{\prime}(\mu \mathrm{H})$ & 1.062 & 1.188 \\
\hline$L_{m}(\mu \mathrm{H})$ & 1.792 & 1.863 \\
\hline
\end{tabular}

Using Method B, the stray capacitances and inductances were determined by fitting the network model to all 23 sets of experimental data over the frequency range from $2.56 \mathrm{kHz}$ to $496.5 \mathrm{kHz}$. Table 3 also gives the parameters identified by Method B. It can be seen that the values of three stray capacitances in Fig.2 determined by Method A (averaged) and Method B are fairly close. One set values of stray capacitances have been used for the simulation of the primary current of the test transformer under a $150 \mathrm{~V} 25 \mathrm{kHz}$ square wave voltage excitation using the circuit shown in Fig.2 with the magnetic core modeled by the dynamic circuit described in [14]. Fig.11 depicts the comparison of the simulated and measured primary current with the presence of the excitation voltage. It can be seen that the predicted primary current waveform agrees with the measured one substantially. 


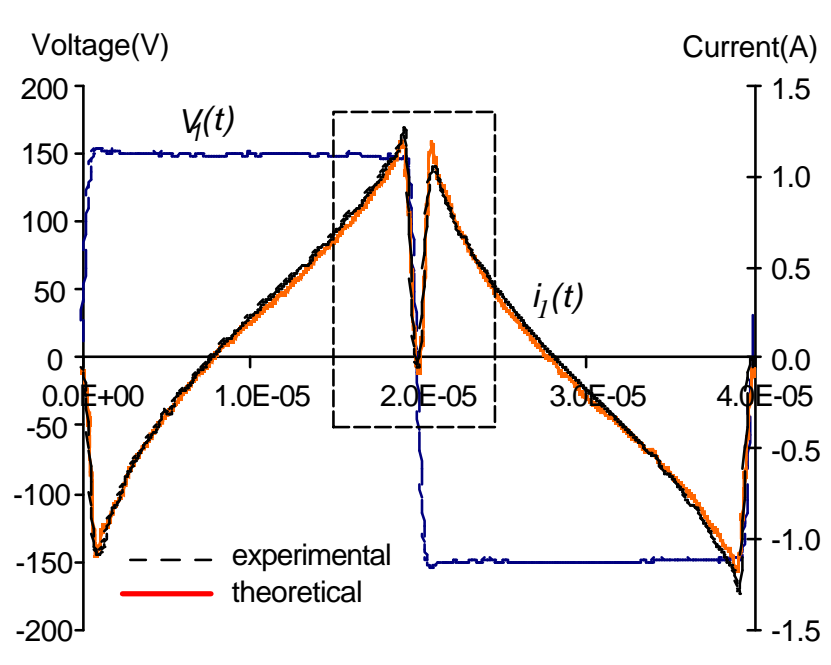

(a)

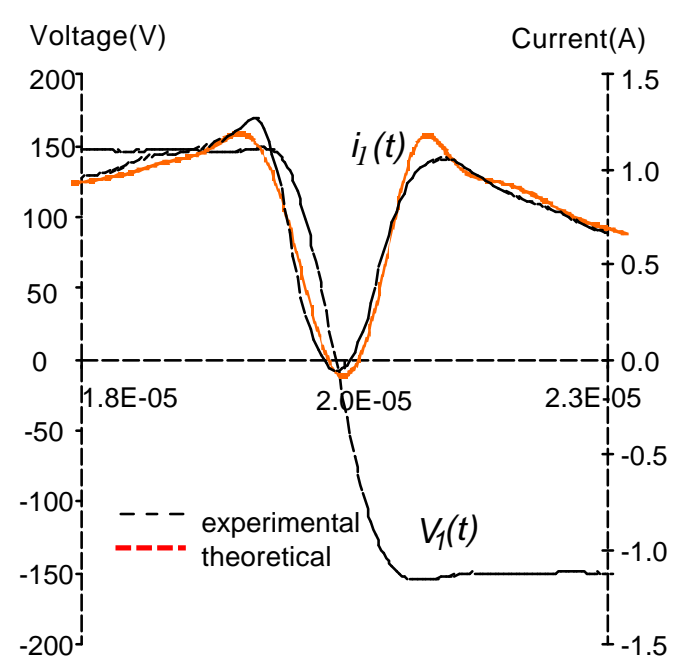

(b)

Fig. 11 Comparison of simulated and measured primary current at $25 \mathrm{kHz}$ no load with $C_{p}=2.65 \mathrm{nF}$, $C_{s}=0.82 n F, C_{p s}=0.17 n F$ using the circuit shown in Fig.2, (a) waveform in one time period, and (b) enlargement of the part bordered by the dashed line in (a)

\section{Step response approach}

The test transformer can be considered as a single coil inductor when its secondary side is opencircuited. As mentioned previously, the overall effects of stray capacitances in the test transformer can be equivalently modeled by a single lumped stray capacitance connected across the primary terminals as shown in Fig.3, and this single lumped stray capacitance can be experimentally determined by the following steps from the step response approach. Firstly, measure the square wave excitation voltage (which is a $150 \mathrm{~V} 25 \mathrm{kHz}$ square wave voltage in this experimental setup), and the current response of the test transformer to this excitation with the secondary side open circuited by using the main circuit shown in Fig.12. Secondly, predict the inductive current $i_{L}$ by using the general dynamic ladder network model of high frequency magnetic cores [13]. Thirdly, calculate the capacitive current passing through the single lumped stray capacitance by deducting the calculated inductive current $i_{L}$ from the measured excitation current $i_{s}$. Finally, calculate the stray capacitance $C_{s t r}$ by (9) and (10). The determined stray capacitance and the relevant experimental readings are also tabulated in Table 4. This experimentally determined value of the single lumped stray capacitance has been used in the 
simulation of the simulation of the primary current of the test transformer under a $150 \mathrm{~V} 25 \mathrm{kHz}$ square wave voltage excitation using the circuit shown in Fig.3 with the magnetic core modeled by the dynamic ladder network described in [14]. Fig.13 depicts the comparison of the simulated and measured primary current with the presence of the excitation voltage. It can be seen that the predicted primary current waveform agrees with the measured one substantially.

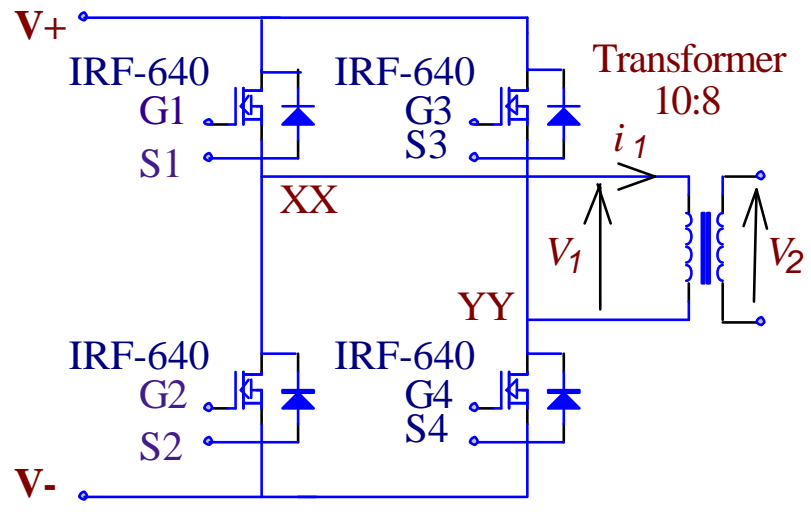

Fig.12 Power circuit of full bridge inverter

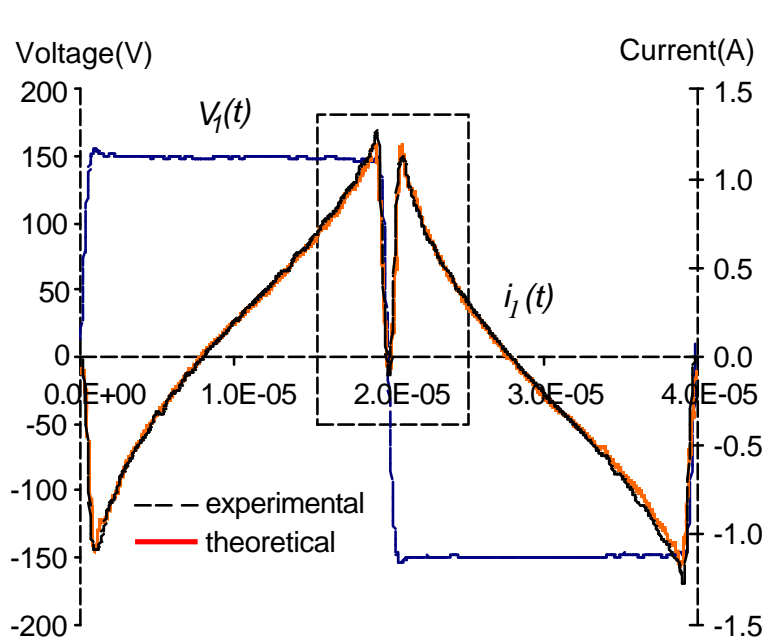

(a)

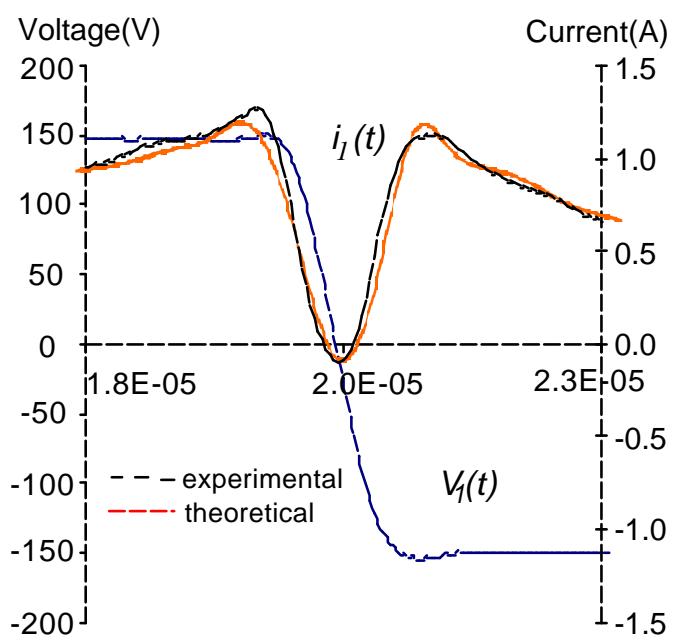

(b)

Fig. 13 Comparison of simulated and measured primary current and secondary voltage at $25 \mathrm{kHz}$ noload with $C_{s t r}=3.70 n F$ using the circuit shown in Fig.3, (a) waveform in one time period, and (b) enlargement of the part bordered by the dashed line in (a)

Table 4. Measured stray capacitance by the step response approach

\begin{tabular}{||c|l|l||}
\hline \multicolumn{1}{|c|}{ Method } & $\begin{array}{l}\text { Determined stray } \\
\text { capacitance }\end{array}$ & $\begin{array}{l}\text { Relevant experimental } \\
\text { readings }\end{array}$ \\
\hline $\begin{array}{l}\text { Step response to square } \\
\text { wave voltage excitation }\end{array}$ & $C_{s t r}=3.70 \mathrm{nF}$ & $\begin{array}{l}\Delta V_{p}=300 \mathrm{~V}, I_{c}=45 \mathrm{~mA} \\
\Delta t=1.72 \mu \mathrm{s}\end{array}$ \\
\hline
\end{tabular}




\section{COMPARISON OF PROPOSED APPROACHES}

In order to compare the proposed experimental techniques for the determination of the stray capacitances in a two-winding transformer, the measured stray capacitances of the test transformer by different methods were listed in Table 5, where $C_{s t r}$ is the equivalent single stray capacitance connected across the primary terminals and approximately equals the sum of $C_{1}$ and $C_{2}$ based on the fact that the leakage inductances of a two-winding transformer are very small in general. It can be seen that the measured results obtained by the two-port network approach are very close with the absolute error being $0.3 \%$ while they have a discrepancy of $6.5 \%$ compared with the result obtained by the step response approach. The reason for this discrepancy might be the assumption that the leakage inductances are too small and the equivalent stray capacitance between two sides can be ignored. This assumption leads to a smaller lumped stray capacitance, which is consistent with the results observed.

Table 5. Stray capacitances in the test transformer measured by different methods

\begin{tabular}{|c|c|c|}
\hline \multicolumn{2}{|c|}{ Approaches } & $C_{\text {str }}(\mathrm{nF})$ \\
\hline \multirow{2}{*}{ Two-port network } & Method A & 3.468 \\
\cline { 2 - 3 } & Method B & 3.458 \\
\hline \multicolumn{2}{|c|}{ Step response } & 3.700 \\
\hline
\end{tabular}

In general, the experimental techniques from the proposed approaches have their own merits and drawbacks and are valid under certain circumstances. The summary of the merits, drawbacks, and conditions of these experimental techniques for determination of stray capacitances in high frequency transformers are listed in Table 6.

\section{CONCLUSIONS}

Several experimental techniques for the determination of stray capacitances of two-winding transformers with the frequency-dependency taken into account have been presented in details. Two 
of the methods under investigation are based on the two-port network approach and they can be used for the determination of three lumped stray capacitances in the circuit model shown in Fig.2. One method is based on the step response approach and it can be used for the determination of a single lumped stray capacitance in the circuit model shown in Fig.3. These techniques have been verified by experimental determination of the stray capacitances in the test transformer. The merits and drawback of proposed experimental techniques are addressed. It has been shown that the proposed experimental techniques are valid for evaluating the overall effects of stray capacitances in twowinding transformers under certain circumstances with satisfactory accuracy. The practical stray capacitance measurement techniques described here provide simple guidelines for practicing engineers to model high-frequency transformers with realistic transient features in circuit designs and simulations.

Table 6. Comparison of experimental techniques for determination of stray capacitance

\begin{tabular}{|c|c|c|c|}
\hline \multirow[b]{2}{*}{ Approaches } & \multicolumn{2}{|c|}{ Two-port Network } & \multirow[t]{2}{*}{ Step-response } \\
\hline & $\begin{array}{l}\text { Single frequency } \\
\text { (Method A) }\end{array}$ & $\begin{array}{l}\text { Multi-frequency } \\
\text { (Method B) }\end{array}$ & \\
\hline Merits & $\begin{array}{l}\text { Account for proximity } \\
\text { effect and parameters } \\
\text { as function of } \\
\text { frequency }\end{array}$ & $\begin{array}{l}\text { Account for overall } \\
\text { proximity effect and } \\
\text { high accuracy }\end{array}$ & $\begin{array}{l}\text { Including effects } \\
\text { of all factors in } \\
\text { stray capacitance }\end{array}$ \\
\hline Drawbacks & $\begin{array}{l}\text { Require too much } \\
\text { computing power if a } \\
\text { great number of } \\
\text { experimental tests are } \\
\text { to be processed }\end{array}$ & $\begin{array}{l}\text { Require a number of } \\
\text { open and short } \\
\text { circuit tests for a } \\
\text { wide range of } \\
\text { frequencies }\end{array}$ & $\begin{array}{l}\text { Require non-linear } \\
\text { magnetic core } \\
\text { model and } \\
\text { detailed test data } \\
\text { under square } \\
\text { wave voltage } \\
\text { excitation }\end{array}$ \\
\hline Conditions applied & Nil & $\begin{array}{l}\text { Linear frequency } \\
\text { dependence of } \\
\text { inductance }\end{array}$ & $\begin{array}{l}\text { Leakage } \\
\text { inductances of } \\
\text { transformer with } \\
\text { magnetic core can } \\
\text { be ignored }\end{array}$ \\
\hline
\end{tabular}




\section{REFERENCES}

[1] E.C. Snelling, "Soft Ferrites-Properties And Applications", Butterworhts, 1988

[2] F.M. Tesche, M.V. Ianoz, and T. Karlsson, "EMC analysis and computational models", New York: John Wiley \& Sons, Inc., 1997

[3] F. de Leon and A. Semlyen, "Efficient calculation of elementary parameters of transformers", IEEE Trans. on Power Delivery, Vol.7, No.1, January 1992, pp.376-383

[4] B. Cogitore, J.P. Keradec and J. Barbaroux, "The two-winding transformer: an experimental method to obtain a wide frequency range equivalent circuit”, IEEE Trans. on Instrumentation and Measurement, Vol.43, No.2, April 1994, pp.364-371

[5] F. Blache, J. Keradec and B. Cogitore, "Stray capacitance of two winding transformers: Equivalent circuit, measurements, calculation and lowing", Conference Record of the 1994 IEEE industry Application Society Annual Meeting, Vol.2, pp.1211-1217

[6] E. Laveuve, J. Keradec and M. Bensoam, "Electrostatic of wound components: analysis Results, Simulation and experimental validation of the parasitic capacitance", Conference Record of the 1991 IEEE industry Application Society Annual Meeting, pp.1469-1475

[7] A. Baccigalupi, P. Daponte and D. Grimaldi, "On circuit theory approach to evaluate the stray capacitances of two coupled inductors", IEEE IMTC/93 Conference Record, pp.549-553

[8] P. Corsonello, P. Daponte, F. DeGrazia and D. Grimaldi, "On two coupled inductors stray capacitances evaluation for cad-oriented modeling", Proceedings of the $35^{\text {th }}$ Midwest Symposium on Circuit and Systems, 1992, pp.1252-1255

[9] A. Massarini, M.K. Kazimierczuk and G. Grandi, "Lumped parameter models for single- and multiple-layer inductors", Record of IEEE Power Electronics Specialist Conference (PESC'96), Vol.1, pp.295-301

[10] Z. Azzouz, A. Foggia, L. Pierrat and G. Meunier, " 3D finite element computation of the high frequency parameters of power transformer windings”, IEEE Trans. MAG-29, No.2, March 1993, pp.1407-1410

[11] F. Blache, J. Keradec and B. Cogitore, "Stray capacitance of two winding transformers: Equivalent circuit, measurements, calculation and lowing", Conference Record of the 1994 IEEE industry Application Society Annual Meeting, Vol.2, pp.1211-1217

[12] G. Grandi, M.K. Kazimierczuk, A. Massarini and U. Reggiani, "Stray capacitance of single-layer solenoid aircore inductors", IEEE Trans. On Industrial Applications, Vol.35, Issues 5, Sept.-Oct. 1999, pp.1162-1168

[13] H.Y. Lu, J.G. Zhu, S.Y.R. Hui, and V.S. Rams den, "Measurement and modeling of stray capacitances in high frequency transformers", Record of the $30^{\text {th }}$ Annual IEEE Power Electronics Specialists Conference (PESC'99), Charleston, South California, USA, June 27 - July 1, 1999, pp.763-769

[14] H.Y. Lu, J.G. Zhu, S.Y.R. Hui, and Vs.S. Ramsden, "Dynamic circuit modeling of a high frequency transformer", Record of the $29^{\text {th }}$ IEEE Power Electronics Specialists Conference (PESC'98), May 17-22, 1998, Fukuoka, Japan, pp.1479-1485 